\title{
Meanings of Health for Iranian Diabetic Patients: A qualitative study
}

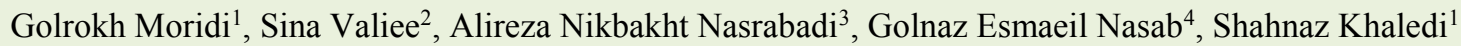

${ }^{1}$ MSN, Lecturer and Faculty Member, School of Nursing and Midwifery, Kurdistan University of Medical Sciences, Sanandaj, Iran

${ }^{2}$ Ph.D., Assistant Professor, Health and Care Research Center, Kurdistan University of Medical Sciences, Sanandaj, Iran

${ }^{3}$ Ph.D., Professor, School of Nursing and Midwifery, Tehran University of Medical Sciences, Tehran, Iran

${ }^{4}$ Student in Environmental Engineering, Faculty of Natural Resources, University of Kurdistan, Sanandaj, Iran

\section{Type of article: Original}

\begin{abstract}
Introduction: Health is an exclusive and subjective phenomenon, and one of the most important situations with regard to perception of health, arises when patients suffer from a chronic disease.

This study was conducted within the qualitative research framework and aimed to explore the meanings of health as perceived by a group of Iranian diabetic patients.

Methods: A descriptive qualitative analysis design was used. Data were collected through semi-structured interviews with 20 participants among diabetic patients, who were admitted to the diabetes care centre of Tohid Hospital of the Kurdistan University of Medical Sciences, Sanandaj, Iran during a ten-month period in 2014. Interviews were transcribed and analysed through conventional content analysis.

Results: Based on the findings of the study, three major health-related themes emerged: 1) the syndrome of the healthy body and the happy heart (physical well-being vivacity, satisfaction, and calmness of the mind), 2) life without compulsory limitations (lack of dietary limitations, No activity limitations, lack of social limitations), and 3) exalted spirituality (satisfying self and others, trusting God, remembering God).

Conclusion: Health care providers should consider the meaning of health in special groups, chiefly in patients with chronic diseases. It facilitates the development of appropriate programmes to improve desirable health levels among diabetic patients.
\end{abstract}

Keywords: Diabetes Mellitus, Health, Nursing, Qualitative Research

\section{Introduction}

In modern society, health is a $\mathrm{n}$ important component, which requires sustained development (1). In recent decades, a person's health has become one of the most important human rights among social groups throughout the world (2). The meaning of health has been extended beyond borders, and different definitions have emerged, owing to diverse geographic regions and cultural views in societies (3). The definition of health may vary by cultural background, and may influence health practices and compliance to medical treatment (4). Individuals perceive health on the basis of their experiences of ill health (5). So, understanding health as a subjective experience can enable health care providers to manage the care giving procedure based on their clients' needs. Furthermore, one of the most important aspects with regard to health perception, manifests when patients suffer from a chronic disease, through which their perception of health is affected $(5,6)$. One of the most common chronic diseases is diabetes mellitus (7). Diabetes is incurable, and has the third highest mortality rate on the planet (8). The probability of the incidence and prevalence of this disease has increased recently (9). In 2004, it was estimated that by 2030, this number will have grown to 366 million (10) and in 2010, the number of people afflicted by diabetes was estimated to increase up to 439 million by

\section{Corresponding author:}

Shahnaz Khaledi, School of Nursing and Midwifery, Kurdistan University of Medical Sciences, Pasdaran St., 66177-13446, Sanandaj, Kurdistan, Iran.

Tel.: +98.918 372 6281; Fax: +98.8733660092. Email: shahnaz_khaledi@yahoo.com

Received: March 08, 2016, Accepted: July 15, 2016, Published: September 2016

iThenticate screening: July 13, 2016, English editing: August 26, 2016, Quality control: September 04, 2016

(C) 2016 The Authors. This is an open access article under the terms of the Creative Commons Attribution-NonCommercialNoDerivs License, which permits use and distribution in any medium, provided the original work is properly cited, the use is non-commercial and no modifications or adaptations are made. 
2030 (8). Current estimates indicate that the number of diabetic patients in Iran is around 3.5 million out of a total population of just over 68 million (11). Previous studies have demonstrated that chronic illnesses such as diabetes can influence a person's perception of health (12). In addition, the attitudes and beliefs regarding health undoubtedly play an important role in promoting healthy behaviour (13). Therefore, the understanding of diabetic patients perceptions can help the development of precautionary programmes for diabetics (14). Although the concept of health is gaining more importance and it has constantly been improved and changed by the passage of time $(15,16)$, few studies are reported to have focused on health and illness, particularly with regard to diabetic patients belonging to different ethnic groups (17). Health is a relative concept; nonetheless, several criteria have been proposed for exploring it through various ethnic and cultural groups $(2,18)$. Prior studies have shown lack of awareness about the concept of health among Iranian Kurdish diabetic patients. Kurds are an ethnic group living in the Middle East, particularly in Iran, who are estimated to be the third largest ethnic group, constituting 9 percent of the total population (19). Consequently, investigating the perception of health-related meaning among this ethnic group can increase the knowledge about the nature of health and its effects. Therefore, this study explored the meaning of health as perceived by Iranian Kurdish diabetic patients in order to develop an appropriate multidisciplinary outlook toward this ethnicity of patients.

\section{Material and Methods}

\subsection{Design}

Considering the aim of this research, a qualitative approach with a conventional content analysis approach was used. Content analysis is a unique qualitative method, which encompasses a host of analytic approaches that offer flexibility to a researcher, and are of theoretical and substantive interest with regards to the case being studied (20, 21).

\subsection{Participants}

The research was conducted over a ten-month period during 2014, in the diabetes care centre of Tohid Hospital at the Kurdistan University of Medical Sciences in Sanandaj, in the center of the Kurdistan province in western - Iran. A purposive sampling method was used to select the candidates for the study from among the diabetic patients who were admitted to the centre. The inclusion criteria for the participants were: having Kurdish ethnicity irrespective of gender, having diabetes type 2, while at the same time having a lapse of at least five years since the diagnosis of diabetes, the absence of psychiatric disorders, and finally, having the ability to communicate. The sample size was determined only when the interviewing stage reached saturation (22). The sample was restricted to 20 because no new data emerged after the twentieth interview. Therefore, the researcher was completely saturated with data to achieve a new understanding and insight about the phenomenon.

\subsection{Data collection}

In-depth, face-to-face, semi-structured interviews were used for data collection. The interviews were scheduled according to the participants` convenience. The participants were encouraged to present their ideas extensively and provide further explanations and details if their narratives were unclear. Moreover, an interview guideline was defined to direct the interviews toward the aims of the study. The interviews began with a general question about health and its perception, and proceeded to seek a deep understanding of participants 'perception. Examples of questions asked during the interview were as follows: When do you feel healthy? What emotions do you experience when you feel healthy? When did you experience a change in your health? What do you experience after the change in your health? Further, the patients were asked to describe all the factors that could affect their health. Twenty interviews were conducted in Kurdish language; each interview was tape-recorded with the participants ' permission. The length of the interviews varied depending on the participant's responses. Each interview spanned 40-90 minutes (average duration: 60 minutes). Each interview was transcribed and then used as a guide for the other interviews. All the interviews were transcribed verbatim in Kurdish language by the corresponding author. Two of the author's colleagues checked the accuracy of the transcriptions by matching the corresponding transcripts with the taperecorded version of the interviews. The Kurdish transcripts were analysed and only the verbatim quotations intended for publication were translated into English. The researchers attempted to translate the participants ' descriptions in a manner in which they closely corresponded to their meaning in Kurdish, while making them grammatically correct for English readers.

\subsection{Rigor}

Through these inquiries, the researchers tried to use a set of measures for increasing the rigor of the data and thereby increase the scientific precision of the results, including: the allocation of a proper place and sufficient time for data 
collection, due communication with participants, using the supplementary views of colleagues, reviewing the participants' hand writing and examining the data by all engaged researchers.

\subsection{Ethical Considerations}

This study was approved by the research committee of the Kurdistan University of Medical Sciences, no.572.14. This study was approved by the code of ethics of the Ethics Committee of Kurdistan University of Medical Sciences, no: muk.rec.1387.572.14. All participants were volunteers and written consent was obtained from each of them in which the voluntary nature of the participation was mentioned. The participants were assured that they could leave the study at any time even after they had signed the consent form. They were assured that their care would not be affected if they chose not to participate in the study. They were also assured of the data confidentiality; this meant that their names and other significant details, that might reveal their identity, would not be published in the study report. All the participants' names were changed into codes during the transcription of the interviews, data was locked in separate locations and the coded information was used for data analysis and discussions.

\subsection{Data Analysis}

In this study, the conventional content analysis was used for data analysis; this method is generally adopted with a study design which aims to describe a particular phenomenon. This type of design is usually appropriate when the existing theory or research literature on a phenomenon is limited (20). The researchers defined the categories on the basis of the type of data and avoided using predetermined categories. All data were meticulously scrutinized in order to allow new insights to emerge. This method is also described as inductive category development (23), where researchers do not use predetermined data groups. Researchers analysed all the data in order to gain a new insight and expand their knowledge about it. By analyzing the literature that they had collected on the participants, and reading the transcriptions of all the participants' interviews word by word, the codes were created. This process continued until all the codes were sorted into categories. Finally, examples were provided for the concept of each data structure. One of the advantages of this approach is that the results of the participants responses in the study can be obtained without imposing preconceived categories or theoretical perspectives $(20,24)$.

\section{Results}

Twenty diabetic patients participated in this study; the participants included seven men with an age range from 53 to 80 years (average age: 68 years) and thirteen women with an age range from 32 to 55 (average age: 40 years). Meanwhile, the average number of years which had lapsed since diagnosis of diabetes was seven years with a range of 5- 17 years. Based on the thoughts and feelings of the participants, the following three main themes emerged:

1) The syndrome of the healthy body and the happy heart

2) Life without compulsory limitations

3) Exalted spirituality

\subsection{The syndrome of the healthy body and the happy heart}

The syndrome of the healthy body and the happy heart is an important theme that emerged in our study. This theme is a Kurdish idiom concerning health. According to this theme (Bivy bi), health marks the presence of particular characteristics, which is an established symbol in the history of Kurdish literature. It refers to the ancient Kurdish description about health as being associated with not only physical well-being but also vivacity, satisfaction, and calmness of the mind. The syndrome of the healthy body and the happy heart is an accepted concept among the laymen and is considered as an ideal and a prayer for every person. Similarly, the participants wished good health to each other with the idea that health implies a healthy body and a contented heart. One of the participants in the study said, "A person with a healthy and contented heart is well-behaved and kind to others" (P1). The participants always used local terminology to describe their ideas of health, and their descriptions and perception of health indicated that health is tantamount to worshipping God, for them. Another participant said, "Health reflects a healthy and happy heart; physical well-being holds less importance as compared to the human spirit, and, both, the heart and the spirit need to be healthy..." (P 7). The participants mentioned that health incorporates several specific factors like calmness and happiness without any worries; sadness, or any family crises. "Health means that you have achieved peace in your family and home, and as a member of your family, you have exhibited good behaviour. Health means that the child and his or her parents share a cordial relationship, and life is a gift from God that ensures calmness and safety" (P 11). Another participant said, "Health means that we do not have any problems or complaints of illness..." (P6), and, "health brings calmness, and it is like praying to God without having to think about stressful matters..."(P2), and, "when you are healthy, you don't have any complaints and anxiety, and so the few problems 
that people have to face seem petty when they have the support of their families. So, the complaints gradually go away..." (P 18)

\subsection{Life without compulsory limitations}

All the participants mentioned that life without any compulsory limitations is one of the important dimensions of health and that they wished they could eat all kinds of food and participate in any occasion and be like others. One of the women (43 years old) said, "When I eat rice, I need more water, and then I know that I am not healthy but fatigued, and I feel like travelling to the mountains and running away for a longer time, and then I suffer from sleeplessness and my body feels weak" (P 13). Another participant also pointed out to eating limitations. "Sometimes, I want to eat some comestibles that our family bought between us, but I cannot do that, and this is so hard for me" (P 3). Eating limitations also affect their family life. "Sometimes, I think I should eat with my children" (P 1). For some participants, the limitations had led to the feeling that they were different from others "When you can participate in a ceremony or accompany someone, do anything that you want, or eat anything that you like, you feel a sense of freedom from others and you can go anywhere without worrying about your medicines ..., this freedom is very fantastic" (P 15).

\subsection{Exalted spirituality}

In general, spirituality is subjective; the individual and personal concept that each person defines is based on his or her understanding and on the evidence that spirituality improves mental and physical health. Participants' emphasis on achieving exalted spirituality in their lives was tantamount to health for them. Most of the participants primarily belonged to the category that perceived health as exalted spirituality, and believed in satisfying self and others and trusting and honoring God. A woman (52 years old) said, "Some of the people whose heart is near to God have good health, because honoring God helps to heal them, and when the spirit is healthy, the body is healthy. And, a healthy spirit in a healthy body, which believes in prayer and spirituality, finds calmness and peace..." (P 18), and, "healthy patients who have the virtue to trust in God and are honest, don't lose their spirituality, religion or prophet..."(P 11) Another participant said, "When I pray to God, I think about how fortunate I am to be born in this world, and then I am happy....'(P 6).

\section{Discussion}

As the results for this group of diabetic patients indicated, health is composed of the syndrome of the healthy body and the happy heart, life without compulsory limitations, and exalted spirituality. Many studies have shown that health perception is a reflection on, not only health but also health as a culture. For all patients, health perception and points of view are the important factors that affect health behaviour and determine any related behaviour (25, 26). An individual may be ill and yet may feel healthy; therefore, many people can compare their health status during suffering from illness with that in the past $(22,27)$. The themes that emerged in our study showed these instances briefly. In this study, participants talked about the effects of diabetes on physical and psychological health, which indicated that our results were similar to those of other studies $(28,29)$. The most important theme of this study was the syndrome of the healthy body and the happy heart. The patients always used local terminology for health description, and these terminologies have extended meanings. In this context, health is considered as a feeling that can affect all components of the human body, including their physical, psychological, social, emotional, and spiritual facets. This view about health is mainly accepted about diabetes because diabetes affects all aspects of a patient's life $(11,28,29)$. In this study, participants admitted that, not only physical health but also vivacity, satisfaction, and calmness of mind, good relationship with family and good economic status are all considered as aspects of health. Hence, health care professionals should strongly consider the issue that health implies lack of having any problems, complaints, illnesses, etc. Furthermore, physical illness and its adverse effects are important topics in the health experiences of diabetic patients; however, when these patients were healthy, they said that without peace of mind one could not feel healthy. Moreover, in a study about health in Spanish immigrants, Ailinger and Causey found that some concepts of health are related to the patients` psychological point of view and peace of mind, calmness in family, absence of complaints, and so on (30). Pinar et al. assessed the effectiveness of selfefficacy and family inter-relationships among young Turkish patients afflicted with diabetes type I (29). Their study showed that calmness of mind and some other related factors such as relationship among family members, conflicts or compatibility in the family, and emotional situations can affect self-efficacy, and accordingly, these factors affect their overall health. Hence, considering the important effect of calmness of mind on diabetic patients' health perception and points of view, we, as health care professionals, ought to be obliged to associate a disturbed mind with bad health. Overall, by using these implications as the bases of patients 'culture, we can improve health programmes for all patients. One of the most plausible themes in our interviews was health as life without 
compulsory limitations. Miklaucich studied the limitations of life as meaningful health experiences in patients with coronary angina (31). Abazari et al. also demonstrated that diabetic patients have dietary restrictions as well as limitations with regards to bearing children (18). Thomson \& Gifford indicated that trying to keep a balance was the preferred meaning of health for diabetic participants (32). It is more important for the professional health care teams to help diabetic patients feel that they are not different from others and in this regard, consultation with dieticians can help to obviate some part of this limitation of life. Studies also show that having a regular activity program and regular follow- up consultation with other health care professionals can help diabetic patients to expel limitations $(33,34)$. In this article, all participants talked about the importance of the spiritual dimension of health and achieving exalted spirituality. They believed that their faith in God helps them achieve desirable health. Some other studies showed that spirituality is one of the significant factors that can affect health; hence, spirituality plays a very important role in gaining adaptation to a lifestyle, with regards to chronic diseases, and helps patients to manage their health-related problems (35). This theme was plausible in traditional societies; hence, nursing professionals must pay more attention to this influential factor. Patients can adopt a spiritual approach by becoming a member of a religious group, praying, and meditating. Exalted spirituality, in fact, helps patients to cope with the disease, and feel better about their lives $(36,37)$. Hamptoun demonstrated the relation between chronic diseases and women's spirituality (38). He showed that praying helps patients to not only connect with the higher power, but also to relate to each other. Their act of praying is a response to their anxieties about themselves or their families. Walton showed that women with chronic diseases, used prayer to calm themselves and connect with others to support each other and cope with diseases (39). Therefore, health care professionals should be aware of the effects of spirituality on patients' having a chronic disease. The results of our study primarily indicated that the factors that affect health perception include complaining about the illness, side effects and outcomes of the disease, and the extent of the complaints that make the patient feel sick. Hence, the patients felt healthier when they did not complain about their illness. Patients with chronic diseases encountered some social and emotional problems due to changes in their lifestyle (36). Diabetes affects patients` quality of life, and especially their perception and attitude toward health (12). It fully depends on how Patients and health professionals define health $(40,41)$. Due to chronic and acute complaints of diabetic patients, we need to create a programme aiming to reduce these adverse effects and promote self-care for diabetic patients. Especially, a program must be developed based on paying attention to body and mind simultaneously, trying to remove the limitation in life of patients by considering the extent of the limitations and limitations that exist for the patients which compel them to believe that the disease has been brought about just for them. This program should not affect or limit the beliefs and spiritual activity of patients because a person's previous experiences influence the perception of present time, which also impact on their future. Besides, having been brought up in a different society and within a different ethnic group, influences a person's health-related behavior. So, health care providers must manage care situations by enhancing health experience to enable patients' lives with the least limitations, and giving them an opportunity to preserve exalted spirituality.

\section{Conclusions}

Studying health perception among patients with chronic diseases is an important factor that facilitates the development of appropriate programmes, to improve health levels among such patients. In this regard, the professional health-care provider team ought to consider health perception among patients, and then they apply this knowledge for setting up suitable health improvement programs. Nurses need to pay more attention to diabetic patients ' limitations and facilitate a programme to improve their health in conjunction with other health care teams. Although nursing and other health care professionals have the responsibility to help those patients achieve peace of mind, the patients` families should also play an active role in the health care programme and treatment process.

\section{Acknowledgments:}

This study was supported by the research fund of the Kurdistan University of Medical Sciences, grant number no.572.14. The researchers express their most appreciation toward all the reverent patients, whose participation made the doing of this research possible. The authors wish to express their gratitude to Vice Chancellor for Research \& Technology, Kurdistan University of Medical Sciences, Sanandaj, Iran.

\section{Conflict of Interest:}

There is no conflict of interest to be declared.

Authors' contributions:

All authors contributed to this project and article equally. All authors read and approved the final manuscript. 


\section{References:}

1) Stanhope M, Lancaster J. Community \& public health nursing. 5 ed: St.Louis, Missouri: Mosby. 2000.

2) Giger JN, Davidhizar RE. Transcultural nursing assessment and intervention. 4 ed. St.Louis, Missouri: Mosby. 2004.

3) Naidoo J, Wills J. Health Promotion Foundations for Practice. 2 ed: Bailliere Tindall: Elsevier. 2000.

4) Benisovich SV, King AC. Meaning and knowledge of health among older adult immigrants from Russia: a phenomenological study. Health Educ Res. 2003; 18(2): 135-44. PMID: 12729173.

5) Strandmark M. The concept of health and health promotion. Scand J Caring Sci. 2007; 21(1): 1-2. doi: 10.1111/j.1471-6712.2007.00501.x.

6) Tulloch A. What do we mean by health? Br J Gen Pract. 2005; 55(513): 320-3. PMID: 15826449, PMCID: PMC1463144.

7) Rasolabadi M, Khaledi S, Ardalan M, Kalhor MM, Penjvini S, Gharib A. Diabetes Research in Iran: a Scientometric Analysis of Publications Output. Acta Inform Med. 2015; 23(3): 160-4. doi: 10.5455/aim.2015.23.160-164. PMID: 26236083, PMCID: PMC4499294.

8) Shaw JE, Sicree RA, Zimmet PZ. Global estimates of prevalance of diabetes from 2010 and 2030. Diabetes Res Clin Pract. 2010; 87(1): 4-14. doi: 10.1016/j.diabres.2009.10.007. PMID: 19896746.

9) King H, Aubert RE, Herman WH. Global burden of diabetes, 1995-2025: prevalence, numerical estimates, and projection. Diabetes Care. 1998; 21(9): 1414-31. PMID: 9727886.

10) Wild S, Roglic G, Green A, Sicree R, King H. Global prevalence of diabetes: estimates for the year 2000 and projection for 2030. Diabetes Care. 2004; 27(5): 1047-53. doi: 10.2337/diacare.27.5.1047. PMID: 15111519.

11) Azizi F. Diabetes care and prevention in Iran. Diabetes Voice. 2005; 50(4): 15-7.

12) Ragnarson Tennvall G, Apelqvist J. Health-related quality of life in patients with diabetes mellitusand foot ulcers. J Diabetes Complications. 2000; 14(5): 235-41. doi: 10.1016/S1056-8727(00)00133-1. PMID: 11113684.

13) Snoek FJ. Breaking the barriers to optimal glycaemic control-what physicians need to know from patients perspectives. Int J Clin Pract Suppl. 2002; 129: 80-4. PMID: 12166612.

14) Taylor C, Keim KS, Sparrer A, Van Delinder J, Parker S. Social and cultural barriers to diabtes prevention in Oklahama American Indian women. Prev Chronic Dis. 2004; 1(2): A06. PMID: 15663882, PMCID: PMC1183498.

15) Balog JE. The Meaning of Health. American Journal of Health Education. 2005; 36(5): 266-73. doi: 10.1080/19325037.2005.10608195.

16) Lindsey E. Health within illness: experiences of chronically ill/disabled people. J Adv Nurs. 1996; 24(3): 465-72. PMID: 8876405.

17) Hjelm KG, Bard K, Nyberg P, Apelqvist J. Beliefs about health and diabetes in men of different ethnic origin. J Adv Nurs. 2005; 50(1): 47-59. doi: 10.1111/j.1365-2648.2004.03348.x. PMID: 15788065.

18) Abazari P, Irani MD, Babaee S, Shahgholian N. Can i do...? Life with type 2 Diabetes: A phenomenological study. Iran J Nurs Midwifery Res. 2008; 13(2): 94-9.

19) Mohammadpur A, Rezaei M, Sadeghi R. Promoting survival: A grounded theory study of consequences of modern health practices in Ouramanat region of Iranian Kurdistan. Int J Qual Stud Health Well-being. 2010; 5. doi: 10.3402/qhw.v5i2.5069. PMID: 20640020, PMCID: PMC2875965.

20) Hsieh HF, Shannon S. Three Approaches to qualitative content analysis. Qual Health Res. 2005; 15(9): 1277-88. doi: 10.1177/1049732305276687.

21) Krippendroff K. Content analysis: an introduction to its methodology: Thousand Okas, CA: Sage. 2004

22) Strauss A, Corbin J. Basics of Qualitative Research: Techniques and Procedures for Developing Grounded Theory: Newbury Park, CA: Sage Publication. 2014.

23) Mayring P. Qualitative Content Analysis. Forum: Qualitative Social Research. 2000; 1(2), Available from: http://www.qualitative-research.net/fqs-texte/2-00/2-mayring-e.htm

24) Elo S, Kyngas H. The qualitative content analysis process. J Adv Nurs. 2008; 62(1): 107-15. doi: 10.1111/j.1365-2648.2007.04569.x. PMID: 18352969.

25) Cho MO. Health care seeking behavior of Korean women with lymphedema. Nurs Health Sci. 2004; 6(2): 149-59. doi: 10.1111/j.1442-2018.2004.00186.x. PMID: 15130101.

26) Mahasneh SM. Health perceptions and health behaviors of poor urban Jordanian women. J Adv Nurs. 2001; 36(1): 58-68. PMID: 11555050.

27) Corbin JM. The Body in Health and Illness. Qual Health Res. 2003; 13(2): 256-67. PMID: 12643032. 
28) Lawton J, Peel E, Parry O, Araoz G, Douglas M. Lay perceptions of type 2 diabetes in Scotland: bringing health services back in. Soc Sci Med. 2005; 60(7): 1423-35. doi: 10.1016/j.socscimed.2004.08.013.

29) Pinar R, Arslanoglu I, Isguven P, Cizmeci F, Gunoz H. Self-efficacy and its interrelation with family environment and metabolic control in Turkish adolescents with type 1 diabetes. Pediatr Diabetes. 2003; 4(4): 168-73. doi: 10.1111/j.1399-543X.2003.00028.x. PMID: 14710777.

30) Ailinger RL, Causey ME. Health concept of older Hispanic immigrants. West J Nurs Res. 1995; 17(6): 605-13. PMID: 8597228.

31) Miklaucich M. Limitations on life: women's lived experiences of angina. J Adv Nurs. 1998; 28(6): 120715. doi: 10.1046/j.1365-2648.1998.00828.x. PMID: 9888365.

32) Thompson SJ, Gifford SM. Trying to keep a balance: the meaning of health and diabetes in an urban aboriginal community. Soc Sci Med. 2000; 51(10): 1457-72. PMID: 11077950.

33) Puig J, Supervía A, Márquez MA, Flores J, Cano JF, Gutiérrez J. Diabetes team consultation: Impact on length of stay of diabetic patients admitted to a short-stay unit. Diabetes Res Clin Pract. 2007; 78(2): 211-6. doi: 10.1016/j.diabres.2007.03.010. PMID: 17481769 .

34) Stenner KL, Courtenay M, Carey N. Consultations between nurse prescribers and patients with diabetes in primary care: A qualitative study of patient views. Int J Nurs Stud. 2011; 48(1): 37-46. doi: 10.1016/j.ijnurstu.2010.06.006. PMID: 20627198.

35) Flannelly LT, Inouye J. Relationships of religion, health status, and socioeconomic status to quality of life of individuals who are HIV positive. Issues Ment Health Nurs. 2001; 22(3): 253-72. PMID: 11885211.

36) Hampton JS, Weinert C. An exploration of spirituality in rural women with chronic illness. Holist Nurs Pract. 2006; 20(1): 27-33. PMID: 16428969.

37) Valiee S, Negarandeh R, Dehghan Nayeri N. Exploration of Iranian intensive care nurses' experience of end - of - life care: a qualitative study. Nurs Crit Care. 2012; 17(6): 309-15. doi: 10.1111/j.14785153.2012.00523.x. PMID: 23061621.

38) Hampton JS, Weinert C. An exploration of spirituality in rural women with chronic illness. Holist Nurs Pract. 2006; 20(1): 27-33. PMID: 16428969.

39) Walton J, Craig C, Derwinski-Robinson B, Weinert C. I am not alone: spirituality of chronically ill rural dwellers. Rehabil Nurs. 2004; 29(5): 164-8. doi: 10.1002/j.2048-7940.2004.tb00339.x. PMID: 15468741.

40) Johansson H, Weinehall L, Emmelin M. "It depends on what you mean": a qualitative study of Swedish health professionals' views on health and health promotion. BMC Health Serv Res. 2009; 9(191): 1-12. doi: 10.1186/1472-6963-9-191.

41) Valiee S, Peyrovi H, Nasrabadi AN. Critical care nurses' perception of nursing error and its causes: a qualitative study. Contemp Nurse. 2014; 46(2): 206-13. doi: 10.5172/conu.2014.46.2.206. PMID: 24787254. 